\title{
Bicycle Paths: A Way to Sustainable Mobility in Medium Sized Towns
}

\author{
George Kollaros and Antonia Athanasopoulou \\ Department of Civil Engineering, Democritus University of Thrace, Xanthi 67132, Greece
}

\begin{abstract}
Considering that non-motorized transport along with public transport are resourceful forms of mobility, this research aimed to investigate the serviceability of integrated bicycle path networks in towns of medium size. Factors impacting bicycle use in medium sized cities (urban planning, other transport means, adequacy of installations and parking spaces, etc.) have been examined. Bicycle can be something more than a sport or entertainment activity and has the potential to become an efficient means of transport. Xanthi is a medium sized town in Northern Greece. Its total area is $153 \mathrm{~km}^{2}$ and 65,000 people live there. An analysis of the existing traffic schemes in the city has pointed out the necessity of an organized bicycle paths network both cost effective and time saving. The main characteristics of such a network are described, hoping that in its completed form could impose the features of sustainable mobility and would be a paradigm for mid-sized cities in the country. Cars could be kept out of the central part of Xanthi if a bicycle paths network is built using a ring-like scheme, since the residents favor the use of bicycle. Local authorities' plans must encourage the lending of public owned bicycles.
\end{abstract}

Key words: Sustainable mobility, medium-size town, bicycle, network.

\section{Introduction}

It is known that the majority of inhabitants tend to move in areas where journeys (on foot, bicycle or in mechanized transport) require less than a quarter of an hour [1-3]. Thus, the main tool for the evaluation of the quality of accessibility is this time-space relation, usually called "temporal proximity" [4]. Proximity units or urban cells, as defined by Ciuffini [5] in 1995, are the smallest urban spatial units where public transport stops are accessed on foot, because they are close to people's homes and workplaces. Nowadays, most towns tend to organize their planning and development in "proximity units", trying to meet the needs of most residents within their livable area.

Sustainable mobility in a traditional city constitutes an imperative need. It can be achieved through a series of measures and applications, such as pedestrianization followed by aesthetic and operational interventions, street lighting

Corresponding author: George Kollaros, associate professor, research fields: highway design and transportation. modernization and tree plantings, sidewalks broadening and pavement narrowing in order to prevent parking on the road, calming traffic measures, construction of organized parking lots in the perimeter of the town, appropriate management and operation and, finally, the provision of advantages for alternative modes of travel, other than car.

In addition to walking, bicycle represents the most mild and sustainable way of transport [6]. Bicycle is a cheap and endearing means of transport and can be used by whosoever wants to be as flexible as a pedestrian, autonomous in his movements, or wishes to have contact with the city and enjoy his locomotion. Another bicycle qualification is the small street usage and parking space occupation. Space saving is very important for European cities, whose centers have been built in seasons unsuspected of the car. However, the bicycle could become a realistic solution, if the space for it is taken from the automotive; This presupposes a decisive policy willing to collide with existing habits and mentalities.

The bicycle falls into reformation policies. When 
the pedestrian can circulate safely, comfortably and pleasantly because the city is attractive and deserves it, then the bicyclist shows up. His presence is a quality criterion for the urban environment. The density of residence influences the choice of means for the daily locomotion to work more than the degree of mixture of land uses, with the exception of the locomotions on foot and by bicycle. Specifically for these locomotions, a radius of about $100 \mathrm{~m}$ has been determined [7], in which the degree of mixture of local scope uses is immediately and positively associated with them.

Conditions favoring bicycle movement coincide with those characterizing the sustainable city: low car speeds, clean air, low noise levels, beautiful road surroundings, systematically maintained urban flooring, sufficient sign and information equipment [8].

Travel distance and time are basic factors impacting the use of bicycle. Consequently, urban design can affect the decision whether the basic destinations, like schools, working places, shops or public transport stations are located in logic for bicycling distance from residences. In the developed countries with high bicycling rates, bicyclists usually travel relatively short distances. In Ireland, for example, the working bicyclists cover daily $5 \mathrm{~km}$ or less (more than $55 \%$ ), $5 \sim 8 \mathrm{~km}(27 \%)$, and only $17 \%$ more than $8 \mathrm{~km} \mathrm{[9].}$

Cycling accounts for $17 \%$ of all trips in Denmark and $4 \%$ of the traffic in kilometers. Cycling accounts for $24 \%$ of all commuter trips. $85 \%$ of all bike trips are less than $5 \mathrm{~km} .70 \%$ of all trips by bicycle are less than $3 \mathrm{~km}$. Only $2 \%$ of all trips by bicycle are longer than $15 \mathrm{~km}$ [10].

In Switzerland, $5 \%$ of all trips and $10 \%$ of trips to work are made by bike. In Norway, $4 \%$ of all trips are made by bike. In Belgium, $8 \%$ of all trips are made by bike and the average distance cycled per person per day is $0.9 \mathrm{~km}$. In Finland, 9\% of all trips are made by bike with an average distance of $0.7 \mathrm{~km}$ being cycled per person per day. In the country of cyclists, the Netherlands, $27 \%$ of all trips and $25 \%$ of trips to work are made by bike. The average distance cycled per person per day is $2.5 \mathrm{~km}$ [11].

Cycling provides economic (reduced household budget devoted to the private car, reduced working hours lost in traffic jams, reduced health costs because of the regular exercise of the body) and other benefits for the community like the reduction in energy dependence and saving of non-renewable resources. Various advantages of cycle use include the fulfillment of social issues, such as the autonomy and accessibility of all facilities to both young and elderly people or ecological effects distinguishing between local, short-term impacts and non-localized long-term effects. The faced difficulty is the quantification of the advantages of cycling for the community-particularly the economic and environmental benefits. The relevant factors are both numerous and complex and relative calculation models need to be devised [12].

\section{Approaches to Viable City Planning}

Transport planning and engineering is the conventional approach to the arrangement of traffic movements and the exploitation of existing or future infrastructure. Sustainable mobility could arise as a valid alternative approach based on a totally different philosophy. In this last approach, instead of the physical dimensioning, social dimensions are in the first plane. Social dimensions are prioritized in urban forms where the trip lengths are below the threshold needed for maximum use of cycling or walking. Such a scheme would minimize the need for car use. Accessibility and environment of high-quality are allowed at the personal scale in city planning strategies, taking into account all three dimensions of sustainability (social, economic and ecologic) $[13,14]$. Regarding sustainable mobility, there is a need for accessibility to be ensured, while mobility is a fundamental goal in conventional transport planning [15]. This leads in focusing on traffic, particularly on the car, leaving only a little role for 
people. In the center of sustainable mobility are people, either riding in a vehicle or moving on foot. There is also a great difference in scale.

The locality is fading in the conventional large picture. On the other hand, the sustainable mobility approach is very local in scale. Streets are conventionally thought as corridors and built facilities serving the traffic needs. The second approach looks at streets as a space for people. This helps to build a more sustainable vision of cities, instead of just making forecasts for traffic volumes in the near or endmost future. People and traffic are segregated in nowadays transport planning. In an alternative method of management, people and traffic have to be integrated [16]. This mixing of people and traffic helps to promote reasonable travel times, enhancing at the same time the travel time reliability. Such a goal is out of the scope of transport planners seeking to minimize travel time. In this case, traffic has to speed up, while in a local level and having in mind the social dimensions, movement has to slow down.

Conventionally, plans are based on the existing or the expected demand [17]. Plans based on a managerial logic fit best to local scaling and social adaptation viewing on activities people wish to undertake for its own sake. Social and environmental concerns are taken into account with multi-criteria analyses adopted by newly constructed procedures in contrast to procedures strictly adhered to economic evaluations. From the precedent discussion, it is clear that moving to an approach for sustainable mobility means a shift from modeling approaches to scenario development ones. Obviously, actions to reduce the pressure for travel, both in number of trips and in trip lengths, along with the encouragement for modal shift are a prerequisite for sustainable mobility [18]. This is how a greater efficiency in the transport system needs to be pursued. There are many methods to make the transport system in the cities more viable:

(1) improving the quality and the accessibility of public transport and its ability to respond flexibly to the citizens needs;

(2) rendering walking and the use of bicycle more attractive;

(3) limiting the car movement in saturated regions (urban tolls policies, control of entry and parking pricing);

(4) making feasible the high quality levels of life that are not dependent on the car, blunting the psychological barriers towards alternative transport ways and gaining the consent on policies that encourage them;

(5) making transports an essential component of urban planning strategies, economic growth and social cohesion;

(6) composing all the above in order to design a door by door transports system, which will be used as a really integrated citizens network.

\section{Bicycle for Small Cities like Xanthi}

In recent years, several opinions tend to the point that sustainable mobility could only be achieved if technological measures are combined with altered personal behavior forming a successful and balanced transport policy response. A series of plans and projects serving this strategy put at a high-level health and environment issues by-passing the strict satisfaction of traffic demands. The key challenge for sustainable mobility is the modal shift from the car use to walking and cycling on a city level, accompanied with shorter transport distances and improved organization to reduce transport demand.

Cycling had a long tradition in many Greek cities [19], but the economic growth of the country has been accompanied by its ostracism, in profit of mechanically-driven two-wheeled vehicles and car. The bicycle constitutes a criterion and condition of quality. The bicycle is connected with the prospect of city's reformation as a whole. An infrastructure with a size of hardly some hundreds of meters means nothing; The bicycle will only be selected if, in the frame of combined locomotion, mainly with the public 
transport, can cover the entire city. It is worthwhile to convince residents that the bicycle is not a means belonged to the past but a modern component of human future cities. Bicycle can be used by whoever wishes to have a contact with the city and enjoy the surrounding space, whoever wants to be flexible as the pedestrian, and autonomous in his travels, avoiding the environment damage.

Xanthi is a county city with a population of about 60,000 people (results of 2011 National Inventory). About 4,000 bicycles are owned by Xanthi's residents, more than 2,000 by pupils. The percentage of bicycle use is quite larger when compared with other Greek provincial cities. This is due to the more "compact" structure of Xanthi, the relatively small distances and the fairly level terrain—at least in its central part. Moreover, the enforcement of bicycle ways allows the reconstruction of main streets in the city. Various intersections crossed by the bicycle ways have been redesigned on the basis of a new plan. Democracy Square, the central square of Xanthi, has been totally reformed and now is much wider because it has been united to the residency square. This offers a great opportunity to accommodate bicycle lanes and calmed car traffic. None of the existing bicycle paths ends to the central part of Xanthi, suggesting the need for an integrated bikeways network.

In many Xanthi's local streets, bicycles circulate freely along with the cars. However, in some other roads, for safety reasons, bicycles obligatorily use exclusive lanes, and their movement is steady and disciplined. Next to walking, bicycle represents an "innocent" way of locomotion, since it is noiseless, it does not pollute, and it does not consume space and fuels, while it presents the least danger against the pedestrian and its own driver. Bicycle is absolutely compatible with urban regeneration policies, constituting one of the most powerful tools of a strategy towards a viable city.

Two powerful actions that could persuade households to alter their preferences from less sustainable travel modes (e.g., cars) to more sustainable ones, particularly to the bicycle, are: (1) the construction of houses corresponding to their neighborhood and housing attitude; (2) the provision for an excellent public transport and cycling infrastructure. This later action could include reduced polluting travel behavior, such as car driving.

When constructing new or modifying existing neighborhoods, households that have sustainable travel-related attitudes must be provided with houses that combine their housing, neighborhood and travel preferences. Households that favor less sustainable travel modes may be induced into more sustainable travel behavior by building houses that fulfill their housing and neighborhood preferences, while at the same time facilitate the use of sustainable travel modes [20].

\section{Technical Description of Road Transport Infrastructure}

Roads in Xanthi typically have one or two lanes. There is a peripheral road comprised to a large extent by four lanes and a 4-lane divided street with a traffic island in the middle of the roadway. The speed limit in the entire urban web ranges from $50 \mathrm{~km} / \mathrm{h}$ to $60 \mathrm{~km} / \mathrm{h}$. The same limit has also been set for cycle paths. The existing cycle paths have been constructed along the one side of the streets, while the traffic is allowed in both directions. The bicycle routes are painted with red color, even in their cross-section with other streets. Though no change has been noted for motor vehicles, special signage has been employed for bicycle users. Blue signs with white symbols have been installed at the ends of every cycle path project. It is suggested that destination names and distances could be included in the sign symbols.

Although the general instructions for bikeways in Greece provide for a required movement width of $0.80 \mathrm{~m}$ or $1.00 \mathrm{~m}$ as a whole [21], the existing bicycle lanes have widths between $1.1 \mathrm{~m}$ and $1.4 \mathrm{~m}$.

The main existing bikeway is the one connecting 
Xanthi with the settlement of Kimmeria in the east part of the area. The route serves those who have adopted the bicycle as a hobby and ideal way of exercise, as well as the students of Democritus University of Thrace. The bicycle path was designed and realized by the District of Xanthi in 2004.

Within the last five years, when a deep economic crisis has hit the country, the promotion of cycling as a daily means of transport has gained significant popularity among Xanthi's citizens. A bicycle club named Pegasus has hundreds of members and organizes a variety of events to promote the no-car concept in the city. Xanthi accommodates the Polytechnic School of Democritus University of Thrace with five departments having a student population of about 3,500. Most of them move using environmentally-friendly means of transportation, as buses and bicycles. The relatively small distances to be covered help this attitude. The promotion of cycling to and from the university campus plays a major role in an overall environmental and sustainability policy drawn by the municipality and the district authorities. A number of services must be offered to cyclists among staff and students to promote and facilitate their use of a green transport mode. Some of them (e.g., a free fixing station) have to be set up or enhanced over the next two to three years, in parallel with the formation of a complete bicycle paths network surrounding in a ring-like scheme the whole city. An example of such a measure could be the "loan a bicycle" scheme for work trips. Bicycles found in different sites all over the city could be borrowed for a certain time and be returned in the same or some other site. The only added cost for the municipality is to buy and install racks and signs.

The topography in some parts of Xanthi is hilly. So, multi-speed gears may be an appropriate bicycle type. It is worthwhile to note that, even by the late 1980s, walking was a basic habit for the majority of Xanthi's residents. Since that time the rate of car holding has rapidly increased and congestion problems appeared, especially in the central part of the city.

Bicycle routes should be signed if they are continuous, at least $1.5 \mathrm{~km}$ long, and they provide through and direct travel in bicycle-demand corridors or they connect discontinuous segments of shared used paths, bike lanes or other bike routes. Traffic control devices, like stop signs or signals, have to be adjusted so as to give greater priority to bicyclists on the route, as opposed to alternative streets. This could include placement of bicycle-sensitive detectors where bicyclists are expected to stop. Street parking has to be removed or restricted in areas of critical width to provide improved safety to the bicyclists. Practically, this is true in the whole urban web in Xanthi. At points where shorter bicycle routes intersect with a signed bike route, it may be appropriate to add a sign (some suggestions have been posed by the second phase of the traffic study on behalf of the Municipality of Xanthi [22]).

Pavement marking and signing are especially important at the approaches to intersections and at the end of bike lanes. Where a bike lane ends, bicyclists are required to merge with motor vehicle traffic. The appropriate striping when provided encourages lane changes in advance of the intersection. At signalized intersections, the signal timing does not need to be lengthened for bicycles to cross.

The clearance intervals could be calculated using a bicycle speed of $15 \mathrm{~km} / \mathrm{h}$ and a bicyclist's perception-reaction-braking time of $2.5 \mathrm{~s}$ [23]. In the case of intersections with a width, a median refuge area at least $2 \mathrm{~m}$ wide should be provided. This is the case of only one street in Xanthi in the east-west direction (Fig. 1).

\section{Proposed Integrated Bicycle Routes Network for the City of Xanthi}

A bicycle routes network is proposed for the city of Xanthi. The distance covered in a diagonal sense is about $6.7 \mathrm{~km}$. 


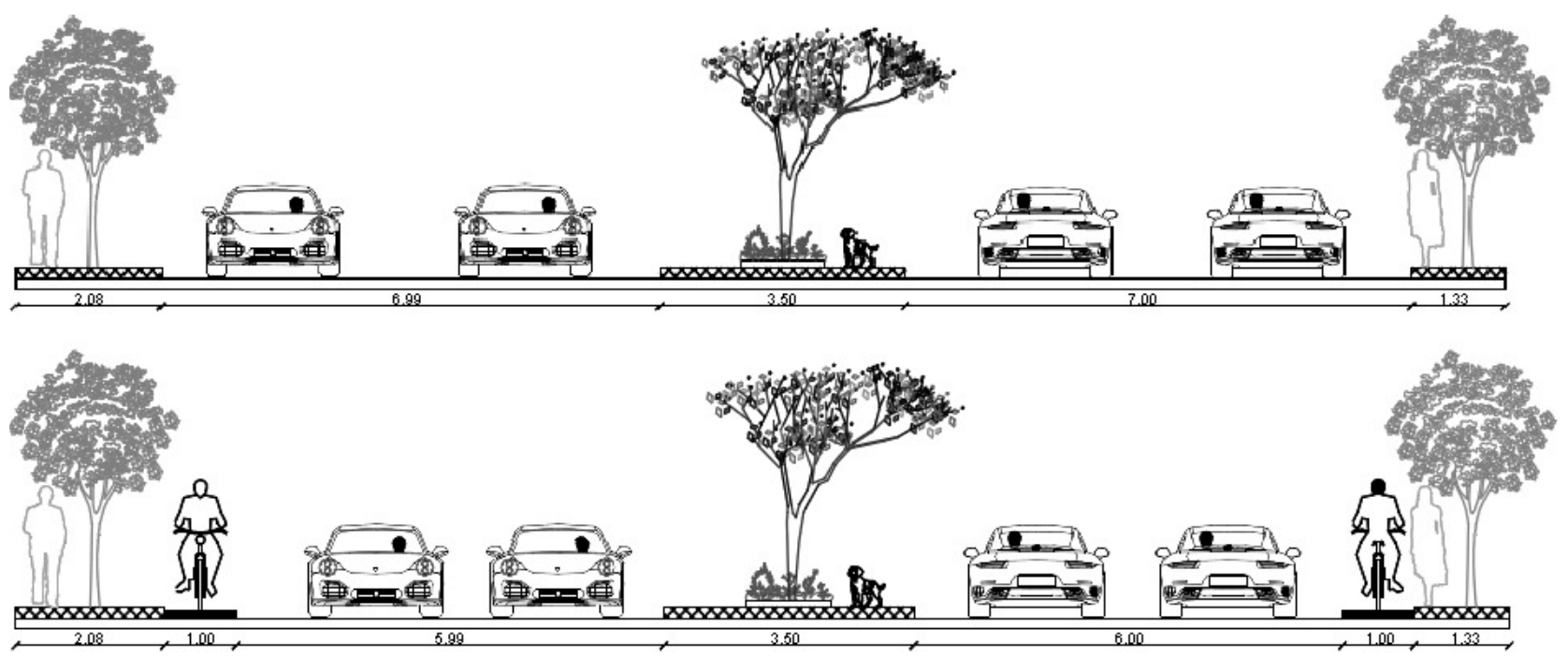

Fig. 1 Cross section for a basic east-west road axis with a bicycle path incorporated to the road body.

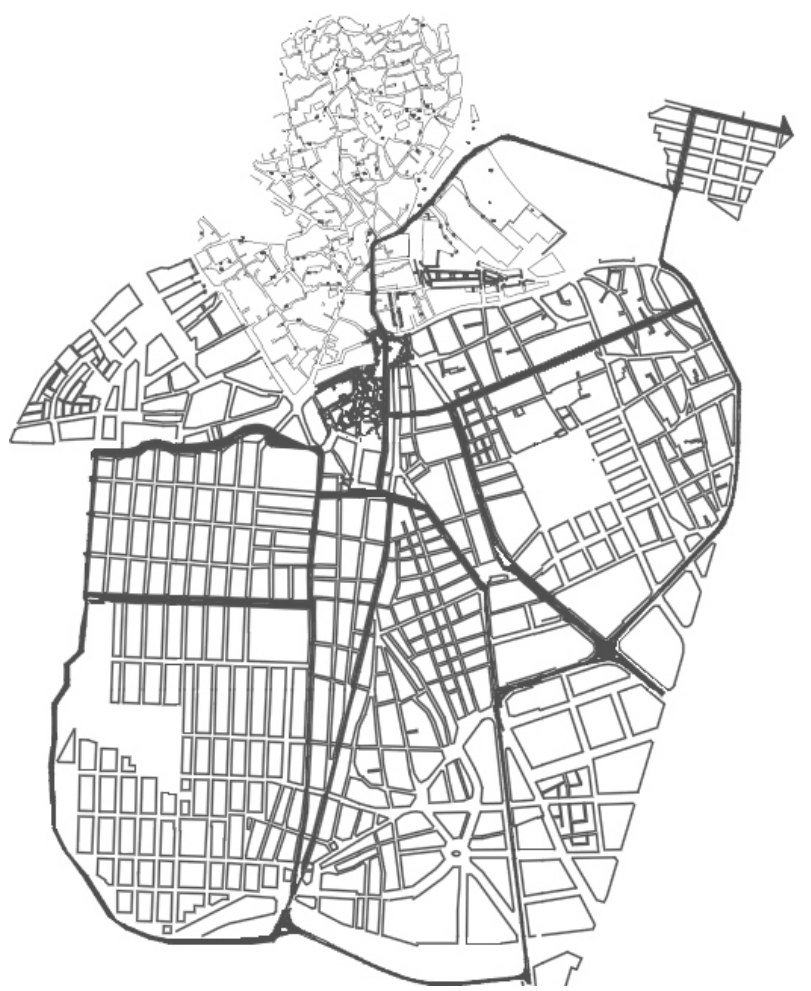

Fig. 2 Proposed bicycle paths network covering almost all neighborhoods in the modern part of Xanthi.

Emphasis has been put to the creation of a comprehensible for the user network having high quality aesthetic characteristics. As shown in Fig. 2, the proposed paths have a closed form to provide continuity and cover almost every neighborhood in the urban web.

In the north, the old town has not been included to the described proposal because of its topography (hilly terrain with climbing slopes) and street configuration (narrow, intricate structures). A separate study is programmed for that part of the city.

In Figs. 3-7, different configurations of bicycle paths are presented. The main road serving as a future exit of the town to the south is recently reconstructed and widened. So, there is a provision for a bicycle route incorporated at one of its sides. The dimensioning of the road is given in Fig. 3. Fig. 4 depicts details of the street still used as a one-way exit from the city. The characteristics are very poor because the surrounding built environment leaves no space for improvements and the entire width is covered by a moving and a parked vehicle. However, this roadway is essential for the bikeways network to be continuous in all its travel way. Bicycles are expected to move on the same side of the road, in both directions.

To enter the city, a visitor uses a one-way road traveling from south to north. It has space enough for a bus to transit parallel to stopped cars. It is proposed to build a bicycle path in the left side, leading to the main square of the city and the old town settlement border (Fig. 5).

Fig. 6 refers to a street type common in a large area of the city (typical for neighborhoods previous decades). 

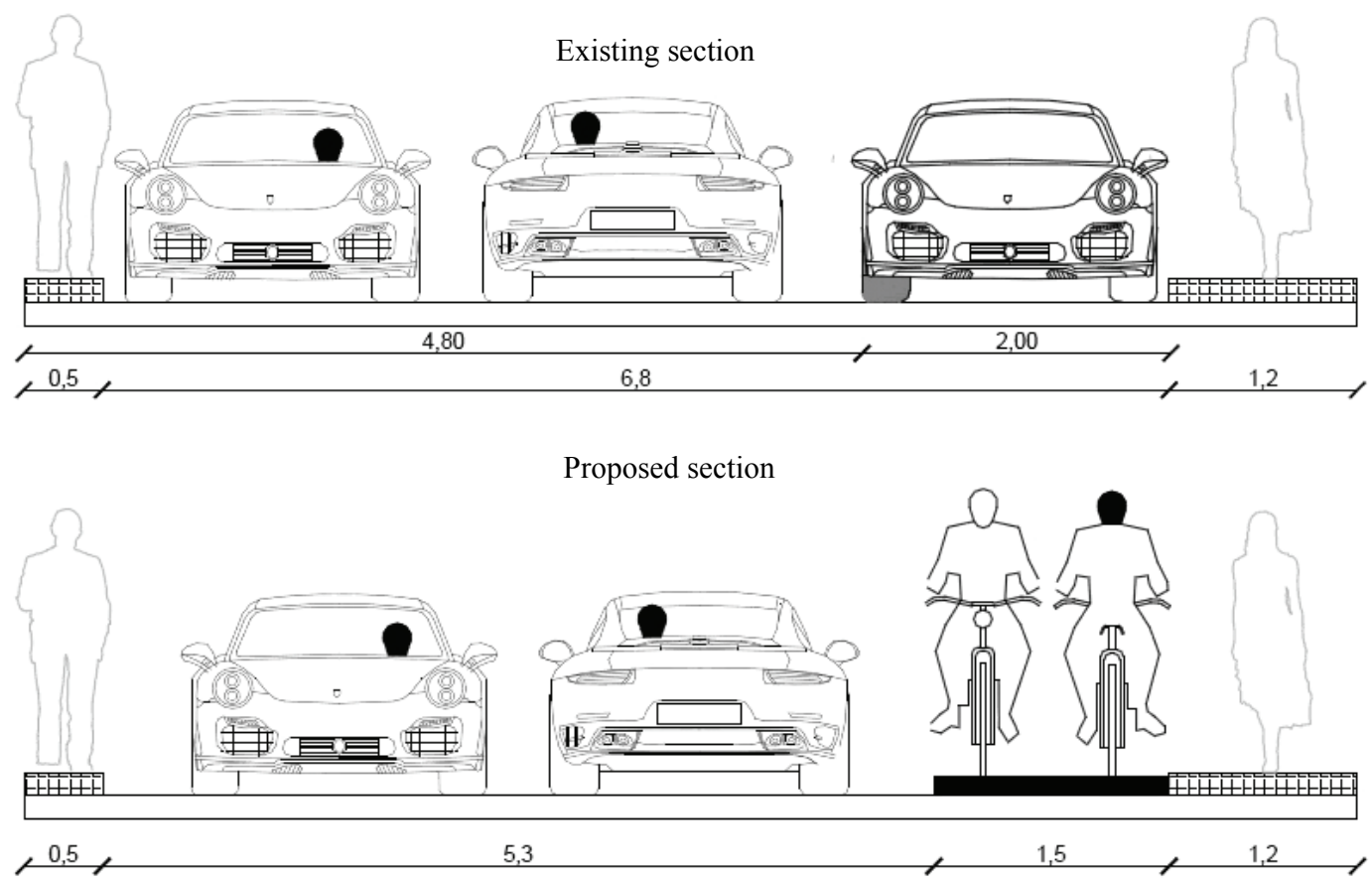

Fig. 3 Cross section for a main south-north road axis with a bicycle path incorporated to the road body.

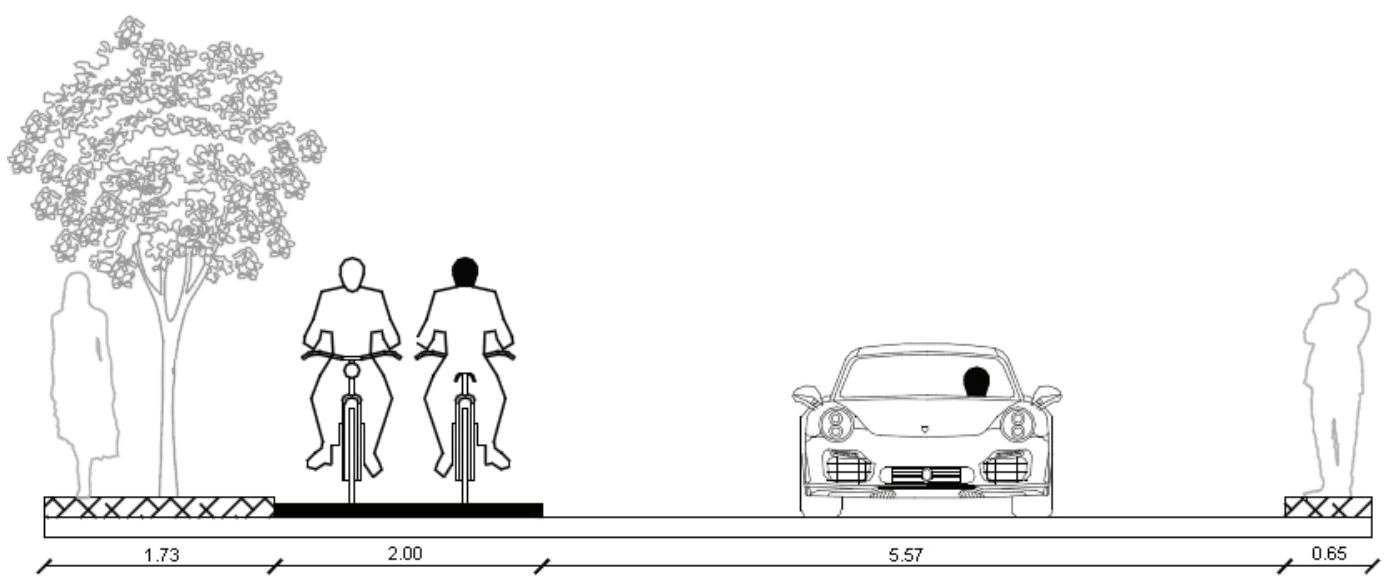

Fig. 4 Cross section for a main street with a bicycle path incorporated to the road body (nowadays south-exit of the city).

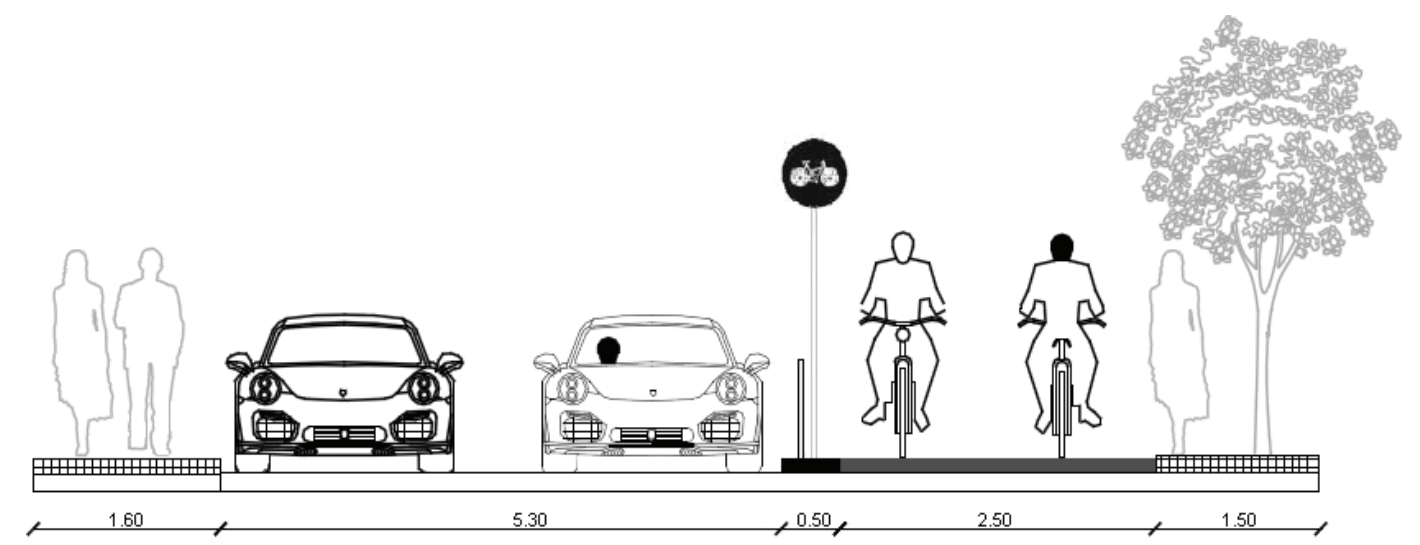

Fig. 5 Cross section for the entrance of the city road axis (south-north) with a bicycle path incorporated to the road body. 


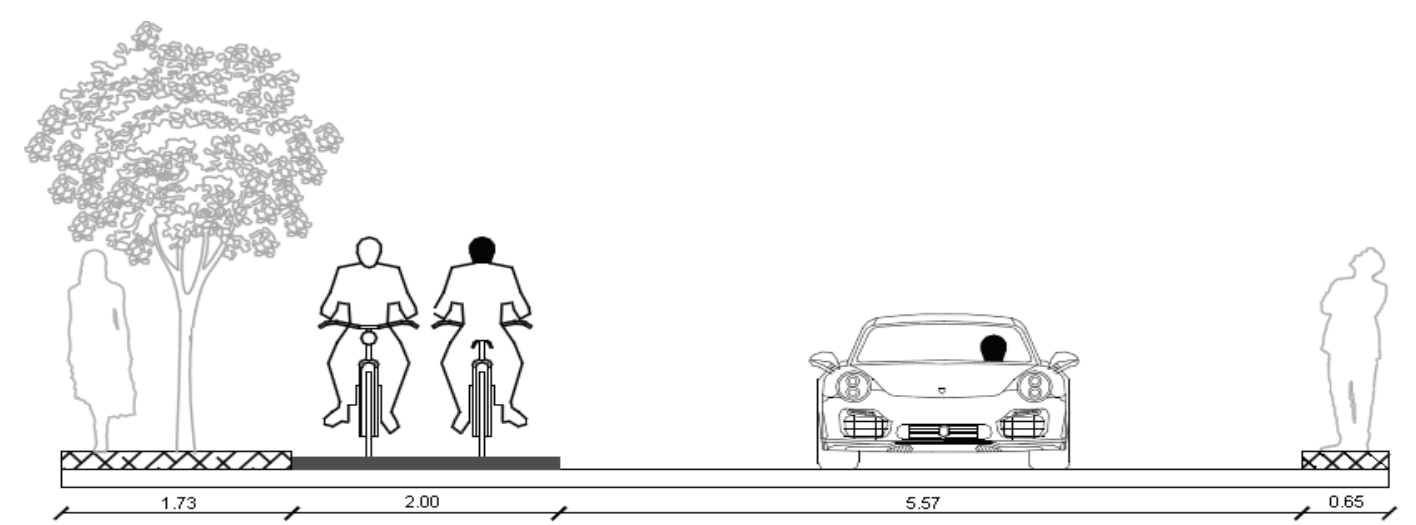

Fig. 6 Cross section for the main S-N road axis (now exit of the city) with a bicycle path incorporated to the road body.

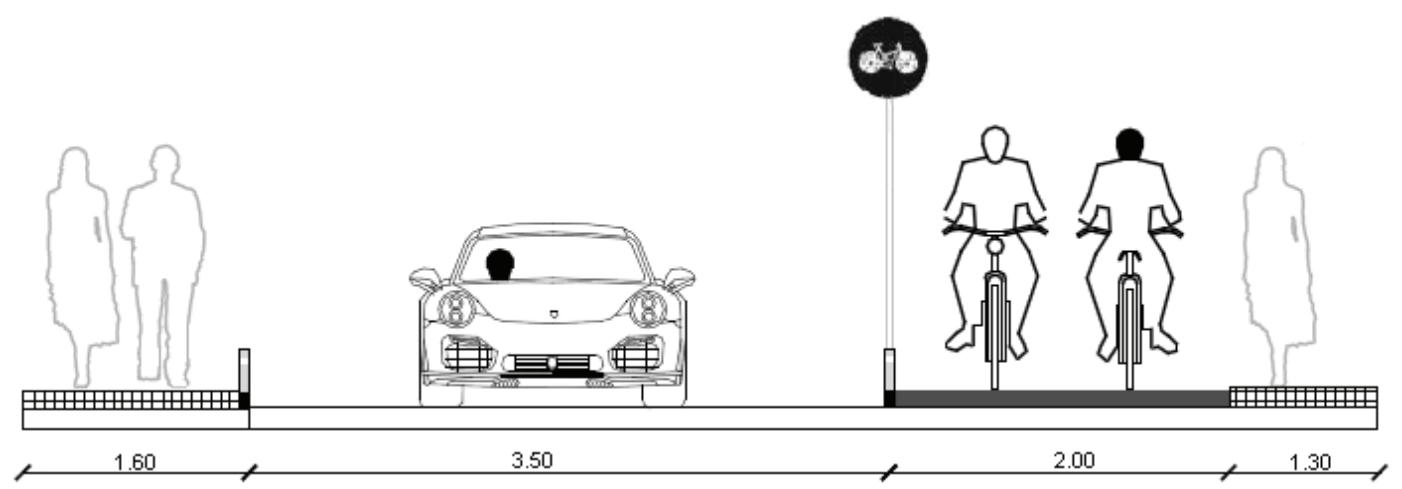

Fig. 7 Cross section which can be used as a standard for of all minor-collector of frontal-streets.

Finally, in Fig. 7, the cross section which can be used as a standard for of all minor-collector or frontal-streets is presented. In any case, sidewalks will be erased relatively to the pavement's level, while bikeways will be laid with a different material and different surface color.

\section{Conclusions and Comments}

There is a high degree of difficulty to fully comprehend and apply measures for sustainable mobility. This is merely due to the great number of parameters, preconditions and complicating factors that favor society needs rather than the satisfaction of demands. However, issues can be raised about effectiveness of the approach employed, as well as the amount of money spent and the manner with which expenditures are made to accomplish intended social wishes.

A holistic approach towards sustainable mobility implies that no decisions can be based solely on social, financial or environmental. It could be founded on experience gained by the interactions between different measures, their effectiveness and cost efficiency and the public's opinion after their enforcement. Bikeways cost money and their merits are often called into question. It is also needed to develop a consistent methodology to justify and evaluate the benefits. Finally, planners, engineers and economists need to work in partnership with business associations to measure and monitor amendments, in an objective manner, with appropriate scale analysis.

An important aspect of the criticism on plans based on the sustainability approach is the watchful judgment of individual local measures against measures covering broader areas, factors, and parameters. Of course, new knowledge is added when different sectors like spatial planning, transport management and demography work more closely.

The quality of infrastructure for the different transport modes and travel-associated attitudes are strongly related. Neighborhoods that have almost no public transportation, walking or cycling 
infrastructure will attract car-oriented households and will also reinforce a positive attitude towards car use.

The central part of the city of Xanthi, in Northern Greece, could be freed from cars if a bicycle paths network is built using a ring-like scheme. This could be relatively easily achieved since the culture of the residents favors the use of bicycle. More measures towards locomotions with bicycle must be planned by local authorities, including the lending of public owned bicycles. For Xanthi's old town settlement, a separate study must be undertaken. The conclusions drawn by the implementation of the bicycle network scheme could be the base for this new design of the circulation in the neighborhoods aiming a sustainable traffic management.

\section{References}

[1] El Husseiny, A. M., and El Husseiny, A. A. 2012. "Integration of Static and Dynamic Spaces in Historic Cairo: A Community Spirit that May Vanish." Procedia-Social and Behavioral Sciences 68: 687-99.

[2] O'Sullivan, S., and Morral, J. 1996. "Walking Distances to and from Light-Rail Transit Stations." Transportation Research Record-Journal of the Transportation Research Board 1538 (1): 19-26.

[3] Chia, J. C. S., and Lee, J. B. 2015. "Variation in the Walking Time to Bus Stop by the Degree of Transit Captivity." Presented at ATRF (Australasian Transport Research Forum), Sydney, Australia.

[4] Waddell, P. 2002. "UrbanSim: Modeling Urban Development for Land Use, Transportation and Environmental Planning." Journal of the American Planning Association 68 (3): 297-314.

[5] Ciuffini, F. M. 1995. The Sustainable City-A European Tetralogy, Part III: Transport and Public Spaces: The Connective Tissue of the Sustainable City. Dublin: European Foundation for the Improvement of Living and Working Conditions.

[6] Lynch, J., and Foley, A. 2011. "Facilitating Cycling to Reduce Urban Sprawl." In Proceedings of Irish Transport Research Network (ITRN 2011), 1-6.

[7] Cervero, R. 1996. "Mixed Land Uses and Commuting: Evidence from the American Housing Survey." Transportation Research Part A 30 (5): 361-77.

[8] Pucher, J., and Buehler, R. 2008. "Making Cycling Irresistible: Lessons from the Netherlands, Denmark and Germany." Transport Rev. 28 (4): 495-528.

[9] Stewart, G., Anokye, N. K., Pokhrel, S. 2015. "What
Interventions Increase Commuter Cycling? A Systematic Review." BMJ (British Medical Journal) Open 5 (8): $1-10$.

[10] The Cycling Embassy of Denmark. 2015. "Facts about Cycling in Denmark." The Cycling Embassy of Denmark. Accessed February 15, 2016. http://www.cycling-embassy.dk/facts-about-cycling-in-de nmark/statistics/.

[11] Top 10 Hell. 2011. "Top 10 Countries with Most Bicycles per Capita.” Top 10 Hell. Accessed October 31, 2015. http://top10hell.com/top-10-countries-with-most-bi cycles-per-capita/.

[12] Vlastos, T. 1998. "Changing the perception of the Private Car in Athens." In Proceedings of the Car Free Cities Conference on Air Quality and Urban Transport, 36-7.

[13] European Parliament. 2011. Economic Aspects of Sustainable Mobility. Brussels: European Parliament.

[14] Banister, D. 2008. "The Sustainable Mobility Paradigm." Transport Policy 15: 73-80.

[15] Banister, D., Stead, D., Steen, P., Åkerman, J., Dreborg, K., Nijkamp, P., et al. 2000. European Transport Policy and Sustainable Mobility. New York: Rutledge.

[16] Marshall, S. 2001. "The Challenge of Sustainable Transport." In Planning for a Sustainable Future, edited by Layard, A., Davoudi, S., and Batty, S. London: Spon Press, 131-47.

[17] Mokhtarian, P. L., and Salomon, I. 2001. "How Derived Is the Demand for Travel? Some Conceptual and Measurement Considerations." Transportation Research Part A 35: 695-719.

[18] Waddell, P., and Borning, A. 2004. "A Case Study in Digital Government: Developing and Applying UrbanSim, a System for Simulating Urban Land Use, Transportation and Environmental Impacts." Social Science Computer Review 22 (1): 37-51.

[19] Iosifidis, K. 2014. The Bicycle in Greece 1880-2012. Athens: Kerkyra Economia Publishing.

[20] Swedish Environmental Protection Agency. 2011. Sustainable Households: Environmental Policy and Everyday Sustainability. Report 6464 from the SHARP (Sustainable Households: Attitudes, Resources and Policy) Research Program.

[21] Ministry of Environment, City Planning and Public Works. 2002. General Guidelines for Bikeways. Athens: Ministry of Environment, City Planning and Public Works. (In Greek)

[22] Municipality of Xanthi. 2015. "Traffic Study: Second Phase.” Municipality of Xanthi. Accessed July 15, 2015. http://www.cityofxanthi.gr/enimerosi/nea/press/8787.

[23] AASHTO (American Association of State Highway and Transportation Officials). 2012. Guide for the Development of Bicycle Facilities. 4th ed. Washington, D.C.: AASHTO. 